\title{
Studying advanced mathematics in England: findings from a survey of student choices and attitudes
}

\author{
Andrew Noyes and Michael Adkins \\ University of Nottingham
}

\begin{abstract}
The UK Government has set a goal that the 'vast majority' of students in England will be studying mathematics to 18 by the end of the decade. The policy levers for achieving this goal include new Core Maths qualifications, designed for over 200,000 students who have achieved good grades at the age of 16 but then opt out of advanced or A-level mathematics. This paper reports findings from a cluster-sampled survey of over ten thousand 17-year-olds in England in 2015. Participants' views on post-16 mathematics are presented and discussed. The main finding is that they are strongly opposed to the idea of compulsory mathematical study, but are less antithetical to being encouraged to study mathematics beyond 16 . We consider how attitudes vary by gender, prior attainment, study patterns and future aspirations. The paper considers the implications of these findings in the current policy landscape.
\end{abstract}

Keywords: advanced mathematics, Core Maths, participation, choice, survey

\section{Introduction}

In 2004, the 'Smith' Report on post-14 mathematics education in England - Making Mathematics Count - argued for the development of "a highly flexible set of interlinking pathways that provide motivation, challenge and worthwhile attainment across the whole spectrum of abilities and motivations" (Smith, 2004, p. 8). The report coincided with national calls for a restructuring of the 14-19 education landscape towards a diploma or baccalaureate-type structure (DfES, 2004, i.e. the 'Tomlinson Report'). 'Smith' came close on the heels of the Roberts review SET for Success (2002) which had highlighted the decline in mathematics and science participation in England's schools, although this was only one of many voices calling for greater participation in science and mathematics in schools and universities (for example, Hawkes \& Savage, 1999; Matthews \& Pepper, 2007; Royal Society, 2008, 2011). Such concerns are not confined to England (Gago, 2004; National Academies, 2007; National Strategic Review of Mathematical Sciences Research in Australia, 2006) and although there are international trends amongst Anglophone young people (Watt et al., 2012), the structural differences in education systems make direct comparison difficult.

In England, young people complete their General Certificate of Secondary Education (GCSE) at age 16. Typically, they study 8-10 GCSE subjects and if they achieve five or more 'good grades' at C or above including English and mathematics they can progress to further academic study. The vast majority of students on advanced study pathways from age 16-18 choose a narrow selection of 3 or 4 A-level subjects. Around $50 \%$ of girls and $40 \%$ of boys in each national cohort are on such pathways. In mathematics, schools and colleges normally require students to have attained at least a GCSE Mathematics grade B before progressing to study the A-level (Matthews \& Pepper, 2007), though many schools prefer an A or A* 
Post print copy of submission to Research in Mathematics Education, 2016.

grade. Over 200,000 students in each cohort gain a GCSE Mathematics grade C or above and then cease their study of mathematics.

The Smith Report did not explicitly call for all students to continue with mathematical study until age 18, but this was implied in the call for mathematics pathways "across the whole spectrum of abilities and motivations" (p.16). The Report set in motion a national programme of curriculum and assessment design which continued for many years (Noyes, Drake, Wake, \& Murphy, 2010), the reverberations of which can still be felt today. The political attention on mathematics at the interface between school, vocational education and training, work and higher education (i.e. 14-18) has continued unabated (ACME, 2011; Deloitte, 2012; Royal Society, 2008; Vorderman, Budd, Dunne, Hart, \& Porkess, 2011).

In 2008 the right-leaning think tank the Reform Group published 'The Value of Mathematics' (Kounine, Marks, \& Truss, 2008) which argued that "winning the battle of the maths economy will be critical to the UK economy" (p. 5). This is not the only place where mathematics and economic value have been linked (Adkins \& Noyes, 2016b; Crawford \& Cribb, 2013; Dolton \& Vignoles, 2002) but the Reform Group report, and the fact that one of its authors later became an influential government education minister (Elizabeth Truss), signalled a strengthening economic argument for increasing post-16 mathematics participation (see Noyes \& Adkins, 2016a, for a more detailed discussion). The Confederation of British Industry (2009) was probably the first organisation to make an explicit public recommendation that "Government needs to ensure that all young people, regardless of what route they choose, study some form of maths or numeracy education after 16" (Recommendation 22, p. 46). The argument was made on behalf of businesses and universities but at that time the government did not publicly take this recommendation on board.

The following year, in 2010, the Nuffield Foundation published its oft-cited 'Outliers' report (Hodgen, Pepper, Sturman, \& Ruddock, 2010) which drew on international comparative data to show that England had one of the lowest rates of post-16 mathematics participation in the developed world; fewer than one in five 16-18 year olds at that time were continuing to study the subject at A-level. 'Outliers' had political impact, and in 2011 the Secretary of State for Education's speech to the Royal Society set out the aspiration that "within a decade the vast majority of pupils are studying maths right through to the age of 18" (Gove, 2011). This idea has cross-party support and was, for example, explicitly mentioned in the Labour Party's election manifesto of 2015: "We will make maths and English compulsory to $\mathbf{1 8}$ to improve the core skills young people need for future employment and study." (www.labour.org.uk/manifesto/education, bold original).

It was clear that England's existing suite of qualifications was inadequate for achieving this goal and so developments were quickly underway to map out the missing pathways for learners. The coalition government of $2010 \mathrm{had}$ commissioned a report on skills education (Wolf, 2011) so part of the mathematics pathways problem had an off-theshelf policy solution, i.e. those falling short of a grade $\mathrm{C}$ would resit the exam. The more challenging problem would be getting an additional 200-250,000 young people in England in each annual cohort to study some form of advanced mathematics. An earlier attempt to plug 
this qualification gap with an applied qualification, AS Use of Maths, had failed for various reasons (Educators for Reform, 2010; Noyes, Wake, \& Drake, 2011) and the antipathy of many students towards post-16 mathematical study is well documented (Brown, Brown, \& Bibby, 2008). Throughout the period from 2004 until now, the numbers of young people studying A-level Mathematics has grown (Noyes \& Adkins, 2016b) but it still remains a minority subject and there are important differences between males and females, both in England and elsewhere (Mendick, 2005, 2008; Nagy, Trautwein, Baumert, Köller, \& Garrett, 2006; National Science Foundation, 2002; Wang, 2012), Participation patterns also vary according to ethnicity and social class (Noyes, 2009) and the school attended (Noyes, 2013).

In 2012 the Royal Society's Advisory Committee on Mathematics Education (ACME) published two documents with advice to government on how to achieve the "vast majority' goal (ACME, 2012a, 2012b). The proposed qualifications would focus on mathematical thinking, problem solving and general applications and be targeted at the $40 \%$ of students in each national cohort who achieve a good grade at GCSE and then stop studying mathematics. Over the ensuing months the idea of 'core maths' became a reality and ACME convened an expert panel, on behalf of the Department for Education (DfE), to provide detailed design advice on new qualifications (Browne et al., 2013). The Core Maths Support Programme was announced late in 2013 with $£ 20$ million funding from the DfE. A pilot for the project began in autumn 2014 and the qualifications were 'rolled out' nationally in September 2015. It is worth noting at this point that this development intersects with a range of other curriculum and assessment reforms, and that such reform processes are not always well aligned (Noyes, Wake, \& Drake, 2013).

It is in the context described above that the present survey was undertaken with 10,131 17-year-olds from 112 schools and colleges in England, early in 2015. The survey was part of a larger project exploring the value of A-level mathematics ${ }^{1}$ and was funded by the Nuffield Foundation. This paper presents largely descriptive analyses of key elements of the survey, particularly items related to students' attitudes to (post-16) mathematical study and how these attitudes vary across the cohort. When the proposal for the project was first discussed with the funder at the start of 2013, it was by no means clear that Core Maths qualifications would materialise. In the event, the survey turns out to have been timely.

We proceed by setting out the survey methodology and sampling approach and then we present analyses of key items including multiple-item scales and demographic data. Whilst we have made use of some inferential tests, scale reliability measures and effect size estimates, the methodological approach is relatively straightforward; the big effects largely speak for themselves. More advanced analysis that makes use of the multi-level nature of the datasets will be reported elsewhere. Here we are interested in exploring how attitudes to

\footnotetext{
${ }^{1}$ The REVAMP project (2013-16) weaves together four strands of quantitative analysis to understand the current and changing attitudes to, participation in, and value of A level mathematics. The project utilises high-quality secondary datasets and includes a large-scale survey of 17-year-olds' understandings of the value of mathematics in their educational and life choices and aspirations. The four quantitative strands of the project are 1) Updated research on the 'economic return' to A level mathematics; 2) An investigation of the nature of changing participation in A level mathematics from 2005-13; 3) Modelling of the relationship between A level mathematics and outcomes in a range of science and social science degree level programmes, and 4) this large-scale survey of 17 -year-olds. These threads are interwoven with a policy trajectory analysis that traces the value(s) attributed to A level mathematics.
} 
Post print copy of submission to Research in Mathematics Education, 2016.

studying mathematics beyond 16 amongst students on advanced study pathways vary by 1) gender, 2) prior attainment, 3) current study patterns and 4) future aspirations.

\section{Methodology}

The project had originally intended to include an online survey but, given the challenges of this approach, our interest in clustering the sample (i.e. students within schools and colleges) to create a multilevel ${ }^{2}$ data structure, and the newfound importance of the survey, we switched to a paper-based version. Through several iterations of the survey and advice from the project's advisory group, a pilot-ready version was developed. A decision was made to keep it as short as possible to increase completion rates and minimise void responses with a maximum completion time of 10 minutes, i.e. short enough to be completed in a registration period at the start of the day.

The survey collected students' examination data at age 16 (GCSE level); their current pattern of study and the qualifications being undertaken; whether they had moved institution following GCSEs; and, their aspirations for education or work beyond school/college. We collected basic demographic data and although these include ethnicity and a social class measure (i.e. parental level of education) these are not used herein due to the reliability of the data and the small subgroups. The final question on the survey asked participants whether they would be willing for us to link their data to the DfE's National Pupil Database (NPD) in future using their name and date of birth. For our purposes, linking would only be undertaken following publication of the summer 2017 examination results in early 2018.

The original design had drawn on items from previous related survey instruments (e.g. as reported in Noyes, 2012; Swan, 2006) but following sustained critique and simplification we ended up using items from TIMSS (Sturman, Burge, Cook, \& Weaving, 2012), the Trends in International Mathematics and Science Survey (see Table 1), in Section $\mathrm{B}$ of the questionnaire. This has the advantage of working with pre-tested items and also allows for some comparison, where appropriate, with those surveys, although there is not space herein to examine those connections. Some of the items required minor modification because of the different target age group. The four-point response scale was agree a lot, agree a little, disagree a little and disagree a lot. There is some discussion in the literature regarding the difference between 4- and 5-point Likert scales (e.g. Adelson \& Mccoach, 2010) and we took a pragmatic decision to adopt the TIMSS categories.

One of the design difficulties when surveying this sample is that, unlike in TIMSS, these students now have different relationships to mathematics. Students might be studying A-level Mathematics, or, they might have failed their GCSE and so be retaking that qualification, or, they might not be studying mathematics at all. These are very different categories of respondent and because we are interested in attitudes to advanced mathematics study we removed the GCSE retake students from the data frame. That left two groups: those actively engaged in A-level Mathematics and those who have, for whatever reason, ceased their study of the subject. It was important to distinguish between these two groups, hence

\footnotetext{
${ }^{2}$ A multilevel structure would allow us to look at the school-level variation as well as student-level variation, although this paper does not explore this aspect of the data
} 
Post print copy of submission to Research in Mathematics Education, 2016.

the difference between the first two sets of questions in Section B (see Table 1). In contrast to TIMSS, we have used 'maths' throughout.

\begin{tabular}{|c|c|}
\hline Survey Item & Notes \\
\hline \multicolumn{2}{|l|}{ GCSE maths (up to the end of year 11) } \\
\hline I enjoyed GCSE maths & These items focused on prior \\
\hline I was pleased with my GCSE maths grade & experiences of mathematics \\
\hline GCSE maths was interesting & learning \\
\hline \multicolumn{2}{|l|}{ I found GCSE maths easy } \\
\hline \multicolumn{2}{|l|}{ Attitudes to maths (general) } \\
\hline I enjoy learning maths & TIMSS \\
\hline Maths is boring & TIMSS \\
\hline I like maths & TIMMS \\
\hline Maths is one of my strengths & Reversed TIMSS \\
\hline I think I am better at maths than other subjects & Reversed TIMSS \\
\hline I am good at working out difficult maths problems & TIMSS \\
\hline I learn things quickly in maths & TIMSS \\
\hline \multicolumn{2}{|l|}{ The value of maths } \\
\hline It is important to do well in maths & TIMSS \\
\hline Maths helps me in my daily life & Modified TIMSS \\
\hline I need maths to learn other subjects & Modified - 'school' removed \\
\hline Being good at maths gives you better opportunities in life & New \\
\hline I need to be good at maths to get into my preferred university & Modified TIMSS \\
\hline I need to be good at maths to get the job I want & Modified TIMSS \\
\hline I would like a job that involves using maths & TIMSS \\
\hline People with A level maths earn more than those with other A levels & New \\
\hline \multicolumn{2}{|l|}{ Choosing maths } \\
\hline All students should be encouraged to study some maths up to age 18 & New \\
\hline All students should have to study some maths up to age 18 & New \\
\hline My parents encouraged me to study maths AS/A level & These final items are aimed \\
\hline My teachers encouraged me to study maths AS/A level & at understanding influences \\
\hline My friends wanted to study AS/A level maths & on decision to study maths \\
\hline
\end{tabular}

Table 1: Items from Section B, question 9 of the questionnaire with notes on the relationship to the TIMSS item

The survey was piloted with a group of around forty students in one institution. A participant debriefing highlighted some wording, conceptual and ordering issues which led to a final draft. This was then formatted by the external survey company who handled all of the distribution, return and data entry.

Our sampling strategy was developed with the intention of conducting multi-level, school-effects analyses and so we employed a cluster design with the aim of recruiting a sample of 12-15,000 students from a range of schools and colleges to allow for a fine-grained analysis, particularly of sub-groups within the sample. However, with resource limitations, the final sample included 10131 responses. These came from 112 institutions which were recruited as follows: 
Post print copy of submission to Research in Mathematics Education, 2016.

(1) Using the most recent (at the time) national A-level dataset, a complete list of schools/colleges in which students were studying A-levels was compiled;

(2) The dataset was used to get an approximate sense of institutional cohort size;

(3) All but the most common school types were removed and we also removed any small institutions with cohort size $<10$;

(4) A 10\% random sample of the full list yielded 201 schools and colleges.

We wrote to the head teachers of all of these institutions inviting them to take part and to designate a contact. The response rate was not as we had hoped so the random sampling process was repeated with the remaining $90 \%$ of institutions not included in the first draw. This process of establishing the sample took around two months with the survey of Year 12 (Grade 11) students conducted in January/February 2015.

We had considered stratifying the sample according to a national profile of school types and cohort sizes but knowing that the sample would ultimately be shaped by schools' willingness to participate, we considered this random sample approach to be sufficiently good. This possibly introduces some bias into the sample due to self-selection of schools but we were able to compare the sample characteristics with national data and some of this is reported amongst the analyses. Another important source of measurement error arises from student self-reporting in the survey. This is particularly problematic when exploring attitudes and this needs to be borne in mind through the analysis below.

All but six schools returned surveys. One challenge was to counter the assumption that because the survey was concerned with mathematics, it was a matter for the mathematics department to organise; they might not necessarily have good access to students not studying mathematics and this could further bias the sample. This risk was, arguably, counterbalanced by their commitment to the research. The maximum possible sample sizes for each institution are not available, so it is not possible to report response rates at that level.

\section{Data cleaning}

The raw dataset included responses from 10,131 students but not all of these were on A-level pathways. Only students with GCSE Mathematics A*-C grades who were studying at least one A-level were retained to leave a sample of 9255. The excluded students who were not studying A-levels (527) comprised four main groups: around 200 did not list a qualification type, 200 were studying BTEC qualifications, around 70 were following International Baccalaureate routes and the remainder reported a variety of other qualification types. The 9255 in the final data frame came from 110 schools/colleges ranging in size from 8 to 341 respondents and with a mean cohort response of 84 . There were 1054 different subject responses including variations, abbreviations and typographical errors. These were cleaned and reduced to 61 categories, many of which were still small. Some of these qualifications were at GCSE level so were removed from the student record to avoid confusion during analysis of study pathways. 
Post print copy of submission to Research in Mathematics Education, 2016.

New variables were constructed including: 1) a binary measure indicating whether students were studying A-level Mathematics ${ }^{3}$ or not, 2) two scale measures relating to attitudes to learning and the value of maths (see Table 2), 3) the total number of $\mathrm{A}^{*}-\mathrm{C}$ grades at GCSE, and d) binary variables indicating whether students were studying physics, chemistry or biology A-levels.

The final aspect of the data cleaning process was concerned with the very large (1291) number of expected topics of study at undergraduate level. These were grouped under the most common undergraduate degrees with joint programmes included under the first named subject. Of particular interest in the analysis herein were those students identifying subjects in science, technology, engineering, mathematics and medicine $\left(\mathrm{STEMM}^{4}\right)$ so a binary measure of intention to study STEMM was also created.

\section{Analysis}

\section{Key characteristics}

The sample was $54 \%$ female. Around $46 \%$ of respondents were, at the time of the survey, engaged in studying A-level Mathematics or Core Maths. This is a higher proportion that one might expect which suggests some systematic exclusion, either in the sampling or on-site surveying, of students not studying mathematics. Only 54 students were involved with the pilot of Core Maths (in four institutions). The large majority $(84 \%, 7769)$ were, at that stage in their studies, intending to progress to university. Of those studying A-level Mathematics in Year 12, 11\% were expecting to stop at the end of the academic year and so not continue for the second year of A-level Mathematics, whereas for those not studying A-level Mathematics in January 2015, 5\% had started (in the previous September) but subsequently 'dropped' the subject.

Elsewhere, we have written about the differential uptake of A-level Mathematics by prior attainment (Noyes, 2009; Noyes and Adkins 2015). For this sample (excluding those for whom a GCSE grade was not available), Table 2 shows that male students at each GCSE grade are more likely to continue with A-level mathematics. Our earlier analysis (Noyes \& Adkins, 2016b) was based upon historical full cohorts of the DfE's National Pupil Database (NPD) and suggested that for the similar cohort four years earlier (i.e. those taking GCSE in 2010 and so at a similar stage in January 2011) the percentages of students completing some A level mathematics was $85 / 56 / 18 / 1 \%$ for students with GCSE Mathematics A*-C respectively. For A* and A grade GCSE students these were $90 / 80 \%$ and $66 / 46 \%$ for males/females respectively. It is important to note a key difference between this present survey data and the NPD data; the latter only records completion of qualifications. For that reason, they are not directly comparable yet participation patterns are remarkably similar, with males from each GCSE grade more likely to be studying (or completing) A-level Mathematics than females. So, although the sample probably has some systematic bias

\footnotetext{
${ }^{3}$ Throughout the analysis 'A-Level Mathematics' includes the small numbers of student doing AS Use of Maths, Core Maths and other advanced mathematics qualifications.

${ }^{4}$ Although the more usual clustering of STEM could be used, there is sufficient overlap of intentions between medicine, biosciences, pharmacy, etc. that it is appropriate to include Medicine. This acronym does appear as a wider umbrella but is admittedly less common than STEM
} 
against non-mathematicians, the data suggest that progression from each GCSE grade category is as expected.

\begin{tabular}{ccc}
\hline $\begin{array}{c}\text { GCSE } \\
\text { grade }\end{array}$ & $\begin{array}{c}\text { \% females } \\
\text { studying maths }\end{array}$ & $\begin{array}{c}\text { \% males } \\
\text { studying maths }\end{array}$ \\
\hline A* & 80.5 & 87.9 \\
A & 52.2 & 72.5 \\
B & 13.3 & 29.0 \\
C & 0.7 & 4.2
\end{tabular}

Table 2: proportion of male and female A-level students studying mathematics in January of Year 12.

Figure 1 shows stacked percentage responses to the survey items in Table 1 for the 9255 respondents. It is notable that the vast majority of this group acknowledge that it is 'important to do well in maths'. Equally strong, but negative, is the disagreement (78\%) with the statement that 'all students should have to study some maths up to the age of 18 '. We discuss this below, taking account of prior attainment, current engagement with mathematics, and other factors.

In the subsequent sections we examine in more detail two sets of items that form scales. Before doing that we take the first four items in Table 1 (regarding GCSE) in order to see the variation in response depending upon whether participants were studying A-level Mathematics or not. Figure 2 indicates the extent to which the whole-cohort responses in Figure 1 mask considerable variations between groups. Those not studying mathematics in Year 12 were far less positive about GCSE Mathematics, experiencing it as less interesting and more difficult than their peers who had chosen A-level Mathematics. Whilst both study groups were generally pleased with their GCSE outcomes, the group no longer studying the subject reported GCSE to be far less interesting and enjoyable. These associations are to be expected and the relationships between a range of factors such as motivation, achievement, classroom culture, course choice and gender have been discussed at length (Nagy et al., 2006; Wang, 2012; Watt et al., 2012). 
Post print copy of submission to Research in Mathematics Education, 2016.

I enjoyed GCSE maths I was pleased with my GCSE maths grade GCSE maths was interesting

I found GCSE maths easy

I enjoy learning maths

Maths is boring

I like maths

Maths is one of my strengths

I think I am better at maths than other subjects I am good at working out difficult maths problems

I learn things quickly in maths

It is important to do well in maths

Maths helps me in my daily life

I need maths to learn other subjects

Being good at maths gives you better opportunities in life I need to be good at maths to get into my preferred university

I need to be good at maths to get the job I want

I would like a job that involves using maths

People with A level maths earn more than those with other A levels All students should be encouraged to study some maths up to age 18

All students should have to study some maths up to age 18

My parents encouraged me to study maths AS/A level

My teachers encouraged me to study maths AS/A level My friends wanted to study AS/A level maths



$\square$ Agree a lot $\quad$ Agree a little $\square$ Disagree a little $\square$ Disagree a lot

Figure 1: Cohort responses to the 24 items listed in Table 1 
Post print copy of submission to Research in Mathematics Education, 2016.

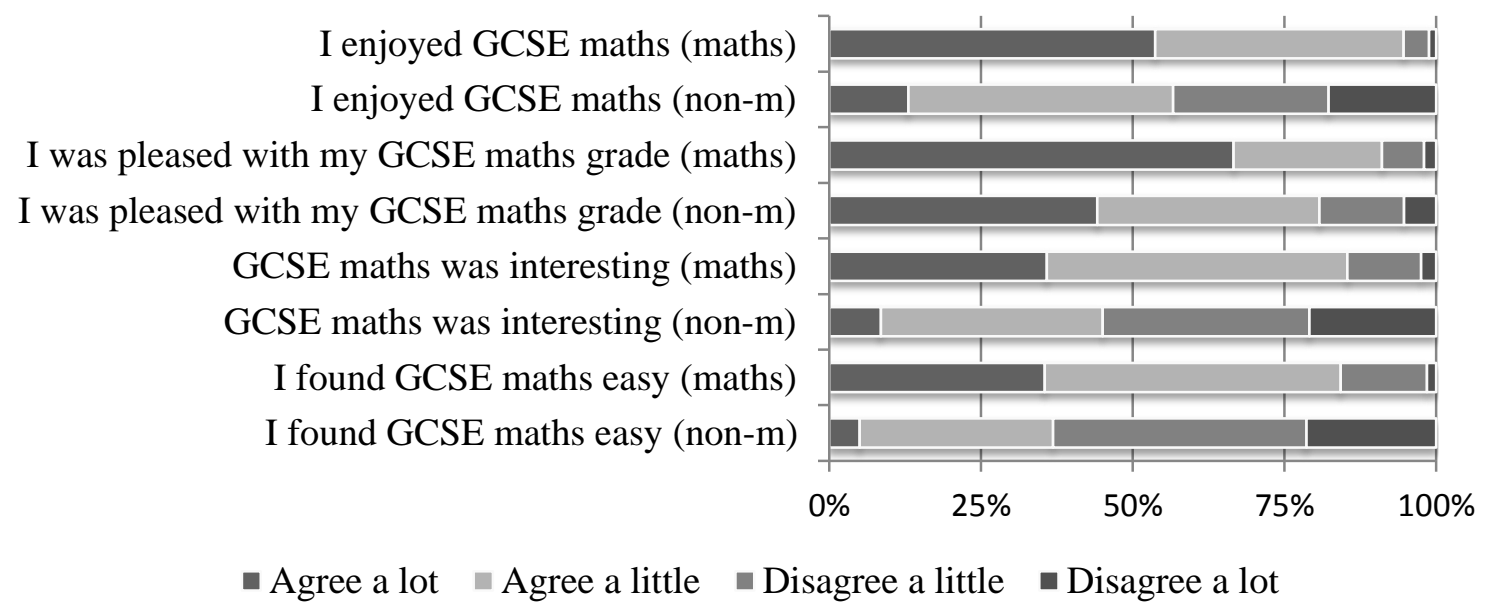

Figure 2: Responses to GCSE mathematics items, by whether studying advanced mathematics (maths) or not (non-m) in Year 12.

\section{Two Scales}

The 24-items in Table 1 explored various aspects of students' self-reported attitudes to mathematical study and their understanding of how their engagement with, and attainment in, mathematics relates to their educational, employment and economic futures. Two sub-scales are of interest.

Seven items in the questionnaire explored general attitudes to mathematics, though the aforementioned problem of the differing relationship to the subject must be borne in mind. These items were designed to form a scale and, given the commonly accepted Cronbach's alpha threshold of 0.8 for reliability, the attitude to maths scale $(\alpha=0.92)$ with a range of values from 7 to 28 was used for further analysis (mean $=16.7$, s.d. $=5.6$ ). In the attitude to maths scale all items correlate strongly with the scale and the Q-Q plots, both here and below, suggest approximate normality.

\section{Attitudes to maths}

- I enjoy learning maths

- Maths is boring (reverse coded)

- I like maths

- Maths is one of my strengths

- I think I am better at maths than other subjects

- I am good at working out difficult maths problems

- I learn things quickly in maths

A scale score was constructed for each respondent and then used to explore the association between prior attainment and attitude to maths. There was a small amount of listwise deletion (1.7\% of cases). Table 3 summarises these mean scale scores by prior grade and whether studying or not studying mathematics. Two things are noteworthy: 1) higher attaining GCSE students have a more positive attitude to maths (i.e. a lower score) and 2) those studying A-level Mathematics have a more positive attitude to maths. These are two distinct groups with different relationships to mathematics, one current and the other historic. 
Post print copy of submission to Research in Mathematics Education, 2016.

It is also impossible to say how closely these figures resemble what they would have been a year earlier, and so attribution of causality is not possible.

\begin{tabular}{ccc}
\hline $\begin{array}{c}\text { GCSE } \\
\text { grade }\end{array}$ & $\begin{array}{c}\text { not studying } \\
\text { mathematics }\end{array}$ & $\begin{array}{c}\text { studying } \\
\text { mathematics }\end{array}$ \\
\hline A $^{*}$ & $17.2(4.9)$ & $11.8(3.6)$ \\
A & $19.2(4.4)$ & $13.4(3.9)$ \\
B & $19.7(4.5)$ & $14.5(3.8)$ \\
C & $21.6(4.3)$ & $17.1(4.5)$ \\
overall & $20(4.6)$ & $12.8(3.9)$ \\
\hline
\end{tabular}

Table 3: mean (and standard deviation) scores on 'Attitude to maths' scale measure, by prior attainment, for those currently studying and not studying maths

The eight items under the 'value of maths' heading also form a strong scale $(\alpha=0.87$, range $8-32$, mean $=18.8$, s.d. $=5.4$ ) and removal of any item has little effect. The scale shows that for non-mathematics students with GCSE grades $\mathrm{C}$ and $\mathrm{A}^{*}$ there is a relatively small effect (Cohen's $d=0.26$ ) of this prior attainment on presently reported attitudes. The differences are, however, statistically significant due to the large sample size. So, for those not studying A-level Mathematics with prior GCSE grades of C (mean = 21.2, s.d. = 4.5) and A* (mean $=20.0$, s.d. $=5.1), t(1897)=4.323, p<0.001$. In contrast, for students with the same prior attainment - in this case GCSE grade A - the effect is much larger (Cohen's $d=1.4$, i.e. a very large effect size) for those studying mathematics (mean $=15.0$, s.d. $=4.2$ ) compared to those not studying mathematics (mean $=20.9$, s.d =4.4). As above, we cannot say whether this sense of the value of mathematics existed prior to deciding to study mathematics or is now part of a post-hoc rationalisation of that decision.

The value of maths

- It is important to do well in maths

- Maths helps me in my daily life

- I need maths to learn other subjects

- Being good at maths gives you better opportunities in life

- I need to be good at maths to get into my preferred university

- I need to be good at maths to get the job I want

- I would like a job that involves using maths

- People with A level maths earn more than those with other A levels

On both of the above scales, male students are about 2.4 points more positive (i.e. smaller) than female students and these differences are significant with medium effect sizes for attitude to maths (Cohen's $d=0.44)$ and for value of maths $(d=0.47)$ in relation to gender.

Those studying A-level Mathematics were more likely to agree with the statement that 'people with A-level Mathematics earn more than those with other A levels' (62\% 'agree a little' or 'agree a lot'), compared to those not studying mathematics $(27 \%)$ on the four point 
Post print copy of submission to Research in Mathematics Education, 2016.

scale. Males are more likely to agree (a little or a lot) with this statement (53\%) than female students (34\%). Similarly predictable is the trend for higher attaining GCSE students to support this statement: $58 \%$ of A* GCSE students compared to $34 \%$ of grade B GCSE students. Despite the fact that test statistics (Mann-Whitney U) are all significant the differences are not as great as one might have expected given the widely-circulated view in policy discourse that A-level Mathematics confers a wage premium (see Noyes \& Adkins, 2016a, for a discussion of the original research and how it has influenced policy). There is anecdotal evidence to suggest that this research is known in schools, at least by teachers, but it does not appear to have persuaded these students.

\section{Mathematics for all}

We now turn to two key questions that are relevant to the debate in England about all students taking some advanced mathematics post-16. The questionnaire asked whether

- All students should be encouraged to study some maths up to the age of 18

- All students should have to study some maths up to the age of 18

We are not able to say what respondents understood by the term 'some maths'. Whilst it was intended to be a broad notion, it might well be that respondents only had A-level Mathematics in mind. Whether this is the case or not is impossible to say but it might not matter that much given the present lack of any meaningful alternative to the traditional Alevel course; Core Maths remains unproven in the qualifications market. Figures 3 and 4 present responses to these items.

Figure 3 shows that those studying A-level Mathematics are generally slightly in favour of all students being encouraged to study some mathematics and there is a similar, inverted pattern seen for those not studying mathematics. The strength of feeling is not particularly great from either group but, as above, (non-parametric) test statistics are all significant. Figure 4 suggests that students feel much more strongly about being compelled to study advanced mathematics. Of most interest here is the group currently not studying mathematics, over $80 \%$ of who are opposed to this idea. This raises important questions in the current policy context and we will return to these in the discussion.

<insert Figure 3 about here>

<insert Figure 4 about here>

These two key questions can also be considered in relation to prior attainment. This is important given that Core Maths qualifications are being targeted at GCSE B/C grade students (Browne et al., 2013) and the propensity for high attaining students to take A-level Mathematics. 
Post print copy of submission to Research in Mathematics Education, 2016.

\begin{tabular}{ccccc}
\hline $\begin{array}{c}\text { GCSE } \\
\text { grade }\end{array}$ & $\begin{array}{c}\text { Agree } \\
\text { a lot }\end{array}$ & $\begin{array}{c}\text { Agree } \\
\text { a little }\end{array}$ & $\begin{array}{c}\text { Disagree } \\
\text { a little }\end{array}$ & $\begin{array}{c}\text { Disagree } \\
\text { a lot }\end{array}$ \\
\hline A* & $27.7 \%$ & $40.0 \%$ & $23.4 \%$ & $8.9 \%$ \\
A & $16.9 \%$ & $39.1 \%$ & $27.7 \%$ & $16.3 \%$ \\
B & $11.5 \%$ & $31.1 \%$ & $32.9 \%$ & $24.5 \%$ \\
C & $7.8 \%$ & $24.7 \%$ & $30.7 \%$ & $36.7 \%$
\end{tabular}

Table 4: percentage of students from each GCSE grade responding to the question 'All students should be encouraged to study some maths up to the age of 18 '

\begin{tabular}{ccccc}
\hline $\begin{array}{c}\text { GCSE } \\
\text { grade }\end{array}$ & $\begin{array}{c}\text { Agree } \\
\text { a lot }\end{array}$ & $\begin{array}{c}\text { Agree } \\
\text { a little }\end{array}$ & $\begin{array}{c}\text { Disagree } \\
\text { a little }\end{array}$ & $\begin{array}{c}\text { Disagree } \\
\text { a lot }\end{array}$ \\
\hline A $^{*}$ & $8.2 \%$ & $16.0 \%$ & $37.6 \%$ & $38.1 \%$ \\
A & $6.3 \%$ & $14.4 \%$ & $35.0 \%$ & $44.3 \%$ \\
B & $6.2 \%$ & $14.1 \%$ & $29.9 \%$ & $49.7 \%$ \\
C & $5.1 \%$ & $13.8 \%$ & $27.5 \%$ & $53.6 \%$ \\
\hline
\end{tabular}

Table 5: percentage of students from each GCSE grade responding to the question 'All students should have to study some maths up to the age of 18 '

Table 5 highlights the policy problem when over $80 \%$ of this sample disagrees with the idea of compulsory mathematical study beyond the age of 16, and most of these strongly. Even the highest attaining GCSE students do not support this idea. These students have been educated in an increasingly neoliberal education system where choice has been a buzzword for years (Ball, Maguire, \& Macrea, 2000; Gewirtz, Ball, \& Bowe, 1995; Smyth \& Hannan, 2006; Tripney et al., 2010) so it is unsurprising that the idea of subject compulsion, particularly for mathematics, is unappealing.

\section{Other features}

Female students agree more strongly than males that their parents encouraged them to study mathematics (68\% agree c.f. $64 \%$ for males) and that teachers encouraged them to study mathematics (78\% agree c.f. $75 \%$ for males). These differences are statistically significant. The data show that students report teachers having marginally more influence than parents upon their decision to study A-level Mathematics. The reported parental impact doesn't vary much according to the GCSE Mathematics grade attained but teachers reportedly have stronger influence upon $\mathrm{A}^{*}$ and A grade students. That said, earlier work highlighted how little some students were aware of the influence of their family milieu on their education choices (Noyes \& Sealey, 2012) so the relationship between student reporting and reality should be treated with caution and needs further investigation.

\section{Future aspirations}

This final part of the survey considered how reported attitudes relate to subject choice patterns and future aspirations. We are particularly interested in the relationship of 
mathematics to science A-levels and then to a slightly wider range of undergraduate study pathways. For example, are those aspiring to study STEMM subjects at undergraduate level engaged studying A-level Mathematics in Year 12?

In this sample, $49 \%$ of students are studying at least one of A-level Physics, Chemistry or Biology. Within each of these subject groups, 87\%, 76\% and 57\% respectively are studying A-level Mathematics during the first year of their A-level programme. Table 6 presents the proportion of students studying A-level Mathematics in each of the probable undergraduate STEMM discipline destinations. This does not tell us who will actually end up studying those subjects but it does suggest that for the physical sciences and engineering, the number of students not studying A-level Mathematics is relatively small. There are few surprises here but good evidence that students recognise the importance of mathematics, at least in the physical sciences and engineering.

\begin{tabular}{lcc}
\hline $\begin{array}{l}\text { Anticipated area } \\
\text { of university } \\
\text { study }\end{array}$ & $\begin{array}{c}\text { Number } \\
\text { of } \\
\text { students }\end{array}$ & $\begin{array}{c}\text { Percentage } \\
\text { studying } \\
\text { mathematics }\end{array}$ \\
\hline Physics & 207 & $93 \%$ \\
Engineering & 482 & $89 \%$ \\
Chemistry & 126 & $82 \%$ \\
Medicine & 505 & $77 \%$ \\
Other Science & 159 & $67 \%$ \\
Computer Studies & 218 & $62 \%$ \\
Biology & 264 & $49 \%$ \\
Psychology & 370 & $23 \%$ \\
\hline
\end{tabular}

Table 6: indicating the proportion of those students planning to study each subject at HE who are studying maths in year 12 .

Another subject of note from outside the STEMM subjects is Economics, with $85 \%$ of those planning to study this subject at undergraduate level undertaking A-level Mathematics in Year 12.

\section{Discussion and conclusions}

This paper reports analyses of a timely survey of 17-year-old students' attitudes to studying advanced mathematics post-16 in England. We were not trying to identify reasons for students not choosing mathematics (c.f. Brown et al., 2008) and do not have the benefit of longitudinal attitudinal data (c.f. Watt et al., 2012) but are interested in considering whether students' reported understandings of the value of mathematics are related to their choice patterns and whether the current policy goals have a chance of success. We have not presented advanced statistical analyses here, in particular multi-level models of how schools and teachers influence students' attitudes and choices, although there is good evidence from earlier studies that the school attended does have an important impact upon the likelihood of choosing A-level Mathematics (Matthews \& Pepper, 2007; Noyes, 2013). 
Post print copy of submission to Research in Mathematics Education, 2016.

Our analysis raises a number of key issues. Firstly, the data show that most students oppose the idea of being compelled to study mathematics; they want to be able to choose to not study mathematics. This is particularly so for the GCSE B and C grade students, the target group for the new Core Maths qualifications (N.B. two thirds of the 54 Core Maths students in the sample had a GCSE Mathematics grade B). This suggests that if government is to achieve its goal that 'the vast majority' are studying mathematics by the end of the decade, a policy based on student choice alone seems unlikely to succeed.

Despite being broadly opposed to the idea of compulsory mathematics, students are fairly equivocal about being encouraged to study the subject. However, the evidence from a range of studies shows that A-level Mathematics is not attractive to the majority of students that achieved GCSE grade B or C; they make positive choices to study other subjects. Given the relationship between mathematical choice and GCSE outcomes (Noyes \& Adkins, 2016b), a major upturn in post-16 mathematics participation seems unlikely without some structural change. Hodgen et al (2014) surmise that participation rates have, or will soon, plateau.

The notion of a baccalaureate-style post-16 qualifications framework has continued since the Tomlinson Report (DfES, 2004). This could normalise the study of mathematics and perhaps make it more culturally acceptable over time. Yet the A-level system in England remains remarkably resistant to reform attempts. An alternative lever for achieving 'vast majority' participation might be the use of accountability measures (DfE, 2014a) or some kind of financial penalty/incentive for schools and colleges. The DfE has combined the baccalaureate and accountability drivers into a new 'TechBacc' performance measure which includes an advanced mathematics requirement, and will be introduced in 2016 (DfE, 2014b). However, this is focused at vocational pathways and is not a 'maths for all' mandate.

Even if a scenario were engineered in which the vast majority would have to study mathematics to 18 , the transition would not be straightforward. The survey data show that $80 \%$ of the Core Maths target group disagree with the idea of compulsory post-16 mathematics and the scale measures (attitude to maths and value of maths) would probably not be different if those learners suddenly found themselves studying the subject; they might well be worse.

The second key issue we want to discuss is regarding the matter of undergraduate STEM admissions. Accepted wisdom is such that A-level Mathematics is considered a necessary prerequisite for many SET disciplines (Royal Society, 2011). At present, some university admissions tutors find themselves in a catch-22 situation and do not require Alevel Mathematics for fear of reducing the pool of applicants in an increasingly competitive market. This survey data suggests that over $80 \%$ of 17 -year-olds that are aspiring to read Chemistry at university are studying A-level Mathematics, a higher figure than that reported by Hodgen et al (2014) from earlier qualifications data, though this might be a peculiar feature of this dataset. Another notable difference is the percentage of possible Economics undergraduates doing A-level Mathematics: $85 \%$ in the survey compared to around $70 \%$ reported by Hodgen et al (ibid.). The question is whether this is close to a tipping point at which a greater number of HEIs might risk a move to requiring A-level Mathematics, for 
Post print copy of submission to Research in Mathematics Education, 2016.

Chemistry degrees for example, which would in turn stimulate mathematics uptake. That said, analysis from another strand of this project raises questions over whether A-level Mathematics completion predicts degree outcomes in Chemistry (Adkins \& Noyes, 2016a).

Thirdly, the data reinforces the oft-reported view that A-level Mathematics is principally taken up by what Matthews and Pepper (2007) termed 'the clever core', i.e. those with GCSE Mathematics A* and A grades. Although their analysis was from the mid noughties, this pattern has changed little. The need for Core Maths qualifications is abundantly clear if Gove's 'vast majority' goal is to be realised but, at the time of writing, the chances of Core Maths succeeding at scale are unknown. Analyses of students' reasons for not studying mathematics (e.g. Brown et al. 2008) suggest that new forms of applied advanced mathematics programmes might help to increase participation. However, if the qualifications do not quickly acquire sufficient exchange value in the jobs market or use value in relation to university admissions and study (Williams, 2012), or if they are seen as a threat to the current level of A-level Mathematics participation (Educators for Reform, 2010), they will not fare well. Given the demise of previous alternative advanced mathematics pathways such as Use of Maths (Noyes et al., 2011) this seems like a particularly precarious policy trajectory.

The final point to note is the ongoing challenge of ensuring more equitable access to advanced mathematics for different social groups. We have touched a little on the gender differences herein, which are manifested in reported attitudinal scores that indicate different positions on intrinsic and extrinsic motivation, the value of others in encouraging choice, and in actual choice patterns. Gender has received a lot of attention in relation to high school mathematics but less work has been focused on the influence on ethnicity and social class factors. More general analysis of GCSE outcomes suggest that gender is the weaker social predictor of outcomes, following social class and ethnicity (Connolly, 2006), but this might not translate well to A-level participation. Previous work (Noyes, 2009), and ongoing analysis from this project, suggest that White British students are less likely, other things being equal, to choose mathematics than Chinese and Indian heritage students.

Further analysis of this dataset will seek to establish the extent to which the school attended predicts the attitude to maths and value of maths scores, the probability of participating in advanced mathematics, and other measures. Here we have focused on timely messages for the current policy trajectory in England. Whilst being locally specific, both the policy priorities and the student attitudes resonate with findings from other parts of the world, particularly the liberal, Anglophone West.

\section{Acknowledgements}

This research is part of the Rethinking the Value of Advanced Mathematics Participation project, funded by the Nuffield Foundation (EDU/41221). The Nuffield Foundation is an endowed charitable trust that aims to improve social well-being in the widest sense. It funds research and innovation in education and social policy and also works to build capacity in education, science and social science research. The views expressed herein are those of the authors and not necessarily those of the Foundation. More information is available at www.nuffieldfoundation.org 
Post print copy of submission to Research in Mathematics Education, 2016.

\section{References}

ACME. (2011). Mathematical needs: mathematics in the workplace and in higher education. London: Royal Society.

ACME. (2012a). Post-16 Mathematics: a strategy for improving provision and participation. London: Advisory Committee on Mathematics Education/Royal Society.

ACME. (2012b). Post-16 Mathematics: planning for success. London: Advisory Committee on Mathematics Education/Royal Society.

Adelson, J., \& Mccoach, B. (2010). Measuring the Mathematical Attitudes of Elementary Students: The Effects of a 4-Point or 5-Point Likert-Type Scale. Educational and Psychological Measurement, 70, 796-807.

Adkins, M., \& Noyes, A. (2016a). Do Advanced Mathematics Skills Predict Success in Biology and Chemistry Degrees? Submited for review to International Journal of Science and Mathematics Education.

Adkins, M., \& Noyes, A. (2016b). Reassessing the economic value of Advanced level Mathematics. British Educational Research Journal, 42(1), 93-116.

Ball, S., Maguire, M., \& Macrea, S. (2000). Choice, Pathways and Transitions Post-16: New Youth, New Economics in the Global City. London: RoutlegeFalmer.

Brown, M., Brown, P., \& Bibby, T. (2008). "I would rather die": reasons given by 16-yearolds for not continuing their study of mathematics. Research in Mathematics Education, 10(1), 3-18.

Browne, R., Koenig, J., MacKay, N., Sheldon, N., Sillcot, N., \& Wake, G. (2013). Report from the expert panel on Core Maths. London: Advisory Committee on Mathematics Education/Royal Society.

CBI. (2009). Stronger together: businesses and universities in turbulent times. London: Confederation of British Industry.

Connolly, P. (2006). The Effects of Social Class and Ethnicity on Gender Differences in GCSE Attainment: A Secondary Analysis of the Youth Cohort Study of England and Wales 1997-2001. British Educational Research Journal, 32(1), 3-21.

Crawford, C., \& Cribb, J. (2013). Reading and maths skills at age 10 and earnings in later life: a brief analysis using the British Cohort Study. Centre for Analysis of Youth Transitions: Institute of Education, University of London.

Deloitte. (2012). Measuring the Economic Benefits of Mathematical Science Research in the UK: Final Report. London.

DfE. (2014a). Reforming the accountability system for 16 to 19 providers: Government response to the consultation on 16 to 19 accountability. London: Department for Education.

DfE. (2014b). The technical baccalaureate performance table measure. London: Department for Education.

DfES. (2004). 14-19 Curriculum and Qualifications Reform: final report of the working group on 14-19 reform. London: Department for Education and Skills.

Dolton, P., \& Vignoles, A. (2002). The return on post-compulsory school mathematics study. Economica, 69(273), 113-142.

Educators for Reform. (2010). The Misuse of Mathematics. London: Educators for Reform.

Gago, J. M. (2004). Increasing human resources for science and technology in Europe. Brussels: European Commission.

Gewirtz, S., Ball, S., \& Bowe, R. (1995). Markets, Choice and Equity in Education. Buckingham: Open University Press.

Gove, M. (2011). Michael Gove speaks to the Royal Society on maths and science Retrieved 17th December, 2012, from 
Post print copy of submission to Research in Mathematics Education, 2016.

http://www.education.gov.uk/inthenews/speeches/a00191729/michael-gove-speaksto-the-royal-society-on-maths-and-science

Hawkes, T., \& Savage, M. (1999). Measuring the mathematics problem. London: The Engineering Council.

Hodgen, J., McAlinden, M., \& Tomei, A. (2014). Mathematical transitions: a report on the mathematical and statistical needs of students undertaking undergraduate studies in various isciplines. York: Higher Education Academy.

Hodgen, J., Pepper, D., Sturman, L., \& Ruddock, G. (2010). Is the UK an Outlier? London: Nuffield Foundation.

Kounine, L., Marks, J., \& Truss, E. (2008). The Value of Mathematics. London: Reform.

Matthews, A., \& Pepper, D. (2007). Evaluation of Participation in A level Mathematics: final report. London: Qualifications and Curriculum Authority.

Mendick, H. (2005). Mathematical stories: why do more boys than girls choose to study mathematics at AS-level in England? British Journal of Sociology of Education, 26(2), 235-251.

Mendick, H. (2008). Subtracting difference: troubling transitions from GCSE to AS-level mathematics. British Educational Research Journal, 34(6), 711-732.

Nagy, G., Trautwein, U., Baumert, J., Köller, O., \& Garrett, J. (2006). Gender and course selection in upper secondary education: Effects of academic self-concept and intrinsic value. Educational Research and Evaluation, 12(4), 323-345. doi: 10.1080/13803610600765687

National Academies. (2007). Rising above the gathering storm: energizing and employing America for a brighter future. Washington, DC: The National Academies Press.

National Science Foundation. (2002). NSF's program for gender equity in science, technology, engineering, and mathematics: A brief retrospective 1993-2001 Arlington, VA: NSF.

National Strategic Review of Mathematical Sciences Research in Australia. (2006). Mathematics and statistics: critical skills for Australia's Future. Canberra: Australian Academy of Science.

Noyes, A. (2009). Exploring social patterns of participation in university-entrance level mathematics in England Research in Mathematics Education, 11(2), 167-183.

Noyes, A. (2012). It matters which class you are in: student-centred teaching and the enjoyment of learning mathematics. Research in Mathematics Education, 14(3), 273290.

Noyes, A. (2013). The effective mathematics department: adding value and increasing participation? School Effectiveness and School Improvement, 24(1), 87-103.

Noyes, A., \& Adkins, M. (2016a). The Impact of Research on Policy: A Case of Qualifications Reform. British Journal of Educational Studies, 1-17. doi: 10.1080/00071005.2016.1159654

Noyes, A., \& Adkins, M. (2016b). Reconsidering the rise in A-Level Mathematics participation. Teaching Mathematics and its Applications. doi: 10.1093/teamat/hrv016

Noyes, A., Drake, P., Wake, G., \& Murphy, R. (2010). Evaluating Mathematics Pathways: Final Report, December 2010 Retrieved from https://www.education.gov.uk/publications/standard/publicationDetail/Page1/DFE$\underline{\mathrm{RR} 143}$

Noyes, A., \& Sealey, P. (2012). Investigating participation in Advanced level mathematics: a study of student drop out Research Papers in Education, 27(1), 123-138.

Noyes, A., Wake, G., \& Drake, P. (2011). Widening and increasing post-16 mathematics participation: pathways, pedagogies and politics. International Journal of Science and Mathematics Education, 9, 483-501. 
Post print copy of submission to Research in Mathematics Education, 2016.

Noyes, A., Wake, G., \& Drake, P. (2013). Time for curriculum reform: the case of mathematics. The Curriculum Journal, 24(4), 511-528. doi: 10.1080/09585176.2013.812973

Roberts, G. (2002). SET for success: The supply of people with science, technology, engineering and mathematics skills. London: Department for Education and Science.

Royal Society. (2008). Science and mathematics education 14-19: A 'state of the nation' report on the participation and attainment of 14-19 year olds in science and mathematics in the UK. London: The Royal Society.

Royal Society. (2011). Preparing for the transfer from school and college science and mathematics education to UK STEM higher education. London: Royal Society.

Smith, A. (2004). Making Mathematics Count. London: The Stationery Office.

Smyth, E., \& Hannan, C. (2006). School effects and subject choice: the uptake of scientific subjects in Ireland. School Effectiveness and School Improvement, 17(3), 303-327.

Sturman, L., Burge, B., Cook, R., \& Weaving, H. (2012). TIMSS 2011: mathematics and science achievement in England. Slough: NFER.

Swan, M. (2006). Collaborative learning in mathematics: a challenge to our beliefs and practices. London: NIACE.

Tripney, J., Newman, M., Bangpan, M., Niza, C., MacKintosh, M., \& Sinclair, J. (2010). Subject choices in STEM: factors influencing young people (aged 14-19) in Education London: Institute of Education/Wellcome Trust.

Vorderman, C., Budd, C., Dunne, R., Hart, M., \& Porkess, R. (2011). A world-class mathematics education for all our young people. Retrieved from http://www.tsmresources.com/pdf/VordermanMathsReport.pdf

Wang, M.-T. (2012). Educational and Career Interests in Math: A Longitudinal Examination of the Links Between Classroom Environment, Motivational Beliefs, and Interests. Developmental Psychology, 48 (6), 1643-1657.

Watt, H. M. G., Shapka, J. D., Morris, Z. A., Durik, A. M., Keating, D. P., \& Eccles, J. S. (2012). Gendered Motivational Processes Affecting High School Mathematics Participation, Educational Aspirations, and Career Plans: A Comparison of Samples From Australia, Canada, and the United States. Developmental Psychology, 48 (6), 1594-1611.

Williams, J. (2012). Use and exchange value in mathematics education: contemporary CHAT meets Bourdieu's sociology. Educational Studies in Mathematics, 80(1), 57-72.

Wolf, A. (2011). Review of Vocational Education - the Wolf Report. Retrieved from https://www.education.gov.uk/publications/eOrderingDownload/The\%20Wolf\%20Re port.pdf 